\title{
Digitalisation and Sustainable work: obstacles and pathways
}

\author{
Lena Abrahamsson
}

Jan Johansson

\section{Abstract}

The aim with this article is to identify obstacles and find pathways for sustainable work in a digital future. We are all concerned about how our work will be in the future; will we be able to handle the new technology or will technology control us? The development is often described in black and white, either as God's gift to mankind or as the wolf is coming. However, the question is not that simple. New technology, such as digitalisation, seldom has in itself a particular way to change our work, whether positive or negative. Future work is shaped here and now, and the development is always possible to influence and control. Based on the vision of Industry 4.0 and observations of the latest technological development that already concretely affects workplaces and people, we have, with the help of theories of sustainable work, discussed what digitalisation can mean for work of the future. We have identified four critical issues that need to be discussed further: 1) The Swedish labour market model under attack, 2) Upskilling, deskilling, or reskilling, 3) Changed gender patterns and 4) Shaping an A and B labour market. The theories of sustainable work are well known and used in working life, in Sweden as well in many other countries, but the road towards digitalisation is complex and filled with traps and pitfalls that need to be handled. To enable positive development, the technical and organisational development needs also to include knowledge of the society, the human and the working environment.

Keywords: Sustainable work; Industry 4.0; skills; digitalisation; gender; Sweden.

\section{Introduction}

In this article we will discuss some obstacles and pathways to sustainable work in the context of digitalisation. "The wolf is coming" and "God's gift to mankind" are two common positions or reactions that follow many technical innovations. This also applies to today's debate on digitalisation, automation and artificial intelligence in working life. "The wolf is coming" indicates a fear that our lives will be deprived of something we want to maintain, while we 
neither can nor really want to refrain from the digitalised society. Here we can recognise the fear that the robots will take over, and that our jobs will diminish. "God's gift to mankind" emphasises the advantages and new opportunities that facilitate and enrich our lives. Here we find techno-optimistic and often technology driven ideas. Society has participated in technological development with these mixed emotions over the last 20 years, and now there are clear signs digitalisation will take a greater leap into not only our everyday lives, but also our work lives in very concrete ways. Conditions that have been considered as given may not be so sustainable in the future. In other words, future work is shaped here and now. In order to find pathways to handle the new technology and design sustainable workplaces for the future, we need to get a picture of what is happening, but we also need a vision of where we want to go and how to get there. In these times of change, we as researchers have to take on the role of the wolf and ask the uncomfortable questions, but also to go between or beyond the two positions "The wolf is coming" and "God's gift to mankind".

\section{The role of work in a digital industrial context}

The German's vision Industry 4.0 (Lasi et al., 2014), and its Swedish companion Smart Industry: a strategy for new industrialisation for Sweden (Regeringskansliet, 2016), paint a bright picture of future working life, where smart machines continuously exchange information with each other, as well as with human workers. The industrial worker will be an expert who makes sure that production runs smoothly. The worker may no longer be "locked" in a control room; instead, the real-time process data and status of machines follow the worker as she moves around the factory. She can solve problems on the spot by remotely interacting with other production operators, experts, suppliers, or customers in multicompetent teams, or she can interact with a humanoid robot that assists in decision-making and analyses. Production control can be done in a digital model far away from the factory. In short, the augmented worker has extended senses and extended memory through technology that takes advantage of and supports human skills, increasing situational awareness, for example, through sensors embedded in the operator's clothes, while keeping an uninterrupted operational vigilance.

An interesting, and perhaps in part a scary, vision is presented by Romero et al. (2016) who, based on the technical core of Industry 4.0, form a typology of the future operators, Operator 4.0. This typology is built on eight characteristics that can be seen as the effects or possibilities of the new technology: Super-Strength Operator (physical interaction) using biomechanical support for increased limb movement, increased strength, and endurance; Augmented Operator (cognitive interaction) using Augmented Reality (AR) for integrating information from the digital to the physical world; Virtual Operator (cognitive interaction) using Virtual Reality (VR) for simulation and training of real situation that might contain risks; Healthy Operator (physical and cognitive interaction) using wearable sensors for monitoring health-related metrics as well as GPS location; Smarter Operator (cognitive interaction) using Intelligent Personal Assistant (IPA) for interfacing with machines, computers, databases, and other information systems; Collaborative Operator (physical interaction) using Collaborative Robots 
(CoBots) for performing repetitive and non-ergonomic tasks; Social Operator (cognitive interaction) using Enterprise Social Networking Services (E-SNS) for interaction between operators and between operators and Internet of Things; and Analytical Operator (cognitive interaction) using Big Data Analytics for discovering useful information and predict relevant events.

The classification points to the numerous possibilities of integrating Industry 4.0 with human labour: some good and some bad. Nevertheless, there is an urgent need to investigate not only how these technologies are designed, chosen and implemented, but also their impacts on work in industry. There are a number of questions that need to be asked, and, as academics, we have a mission to be the social prosecutor who poses the uncomfortable questions. We have identified four such critical issues to discuss further in this article:

- The Swedish labour market model under attack

- Upskilling, deskilling, or reskilling?

- Changed gender patterns

- Shaping an A and B labour market

\section{The Swedish labour market model under attack}

Over the years we have witnessed an increase in labour flexibility, the decline of standard labour contracts, sub-contracting or outsourcing of work (Taylor, 2010), increasing selfemployment, and mounting insecurity (Thompson, 2013). However, it is the use of digital platforms by global enterprises to crowd-source labour to small and micro sized companies all over the world that is reshaping work and employment conditions in the most visible way so far.

The term crowdsourcing was coined by Howe in 2006, and was presented as a new level of sub-contracting. For example, rather than relying on offshore jobs at low-cost locations, companies can outsource functions, once performed by employees, to an amorphous and generally large pool of individuals, using an open call over the Internet (Howe, 2008). The most significant differences between crowdsourcing and a traditional workforce are the higher levels of flexibility, scalability, access to a broad range of skills, and experiences at significantly less cost, coupled with the lack of employment regulations. This strategy appeals to industrial firms, as they are able to access a labour force that can expand and contract on demand, without any significant transaction costs or logistical hurdles. Management control is simultaneously 'at a distance' while remaining all-powerful when directing work tasks and determining the nature of reward. Relationships are fleeting and largely anonymous, with no obligation to provide support or facilities for the workforce.

Another aspect of the new technology is related to Scandinavian industrial sociology. In this field, Lysgaard's (1961) book on the workers' collective is regarded as seminal, one of the classics of its time. Although it is well researched and documented that workers act 
collectively in the workplace, the term 'workers' collective' is rarely used in current Nordic research. It is, for example, well-known that the workers' collective functions as a set of norms, controlling the workers' relations to each other as well as the extent to which deviations from these norms (e.g., a certain type of masculinity, negative attitudes to management, and technological change) are counteracted or accepted. Materialised by this normative system, the workers' collective is based on a culture of resistance that attempts to gain informal control over the work situation. It can also function as a protector of practical and hard physical work, referred to as 'embodied competence' or 'body capital'. Consequently, new technology and new management models are often resisted by the collective system. In this context, Industry 4.0, automated factories, and Internet of Things represent a new technological and managerial landscape to which several reactions are possible. There is a need to analyse the opportunities and challenges represented by the current technological and organisational development, and to create a theoretical platform for the understanding of the transformation of work and workers, based on the workers' collective.

On an aggregated level, this is about the survival of the Swedish labour market model. The Swedish labour market is one of the most harmonious in the world, based primarily on bilateral agreements between the parties, rather than on legislation. In a global internet-based labour market, there is hardly any space for collective agreement and the Swedish labour market model, instead the legislative path seems to be the only way possible. Here is an interesting opening where the Swedish trade unions have long been more co-operative than their European colleagues. Relationship to new technology has often been characterised by "If you can't beat them, join them" (Johansson et al 2013).

\section{Upskilling, deskilling, or reskilling?}

The visions of fully automated factories, Industry 4.0, and Internet of Things not only change the technological landscape of industrial workplaces and organisations, but also cause a qualitative knowledge transformation: from bodily and tacit into more abstract and theoretical knowledge and skills. In the optimistic view, we can read that Industry 4.0 requires workplace learning, as well as continuous education and systems that make use of the workers' skills: i.e., a learning organisation. Using Kern and Schumann's concepts (1974), we can see a clear transformation from the craftsman-like qualification into more technical qualifications. The new demands for teamwork, responsibility, and comprehensive understanding of production flow can be seen as a movement from qualifications dependent on the process, to qualifications more independent of the process (cf. Kern \& Schumann, 1974, 1987; Bright, 1958; Blauner, 1964; Johansson, 1986). What was earlier the workers' tacit knowledge (Polanyi, 1967) will be formalised into theoretical knowledge, digitalised, and used in computers and smart phones. In this transition, we can see contradictory movements of upskilling: rapidly changing skill demands and more theoretical, comprehensive, and communication tasks: and deskilling, fragmentation of individual craft knowledge and whole tasks (Abrahamsson \& Johansson, 2006). 
Whether it is a question of upskilling, deskilling, or reskilling, the transformation of knowledge affects workplace cultures, community of practices, and identities. Individuals and organisations will have to create and recreate qualifications, identity, and gender, when meeting new technology in a changing context. For example, the new knowledge and skills needed may be more abstract and theoretical, but still based on bodily and tacit knowledge, although in new and less physically demanding forms. A common optimistic scenario gives women and other previously underrepresented groups a chance to enter and master different types of industrial work, such as in mining and process industries. Given that this scenario is realised, it does not entail a smooth and unproblematic process. The identity and symbolic aspects of work often lag behind the developments in, for example, technology and qualification demands, resulting in restoring responses during processes of organisational changes (Abrahamsson, 2014). As the workers' collective (cf. Lysgaard, 1961; Fältholm, 1998) is built and sustained by processes of homosocial interaction and identification and on norms controlling likeness between workers, there is reason to investigate how new technology affects these processes. The seemingly robust gender and power relations will be challenged, renegotiated, and ultimately transformed.

\section{Changed gender patterns}

One of the hopes of technological development in the industry is that it will allow for changed gender patterns: a better work environment combined with higher qualification demands that will enable more women to work in the industry, creating better gender equality. But the picture is not so clear-cut. At many industrial workplaces where digitalisation is taking place, it is quite common that technology is associated with masculinity (Berner, 2003; Mellström, 2004). This masculinisation of technology is evident in the discourse of the technology, as well as in the culture of these companies. At traditional male-dominated industrial workplaces, even if the workplaces undergo digitalisation, the connection to masculinity lingers, because of the old strong symbolic links to a traditional blue-collar masculinity (Abrahamsson, 2006; Andersson, 2012; Eveline, 2001; Lahiri-Dutt, 2007, 2012, see also Collinson, 1992; Whitehead, 2002; Willis, 1979). For example, the work is often associated with explicit expressions of a special type of masculinity, "macho-masculinity", which is almost difficult to take seriously and analyse (Somerville \& Abrahamsson, 2003). The fear of being seen as less masculine is a common theme in these kinds of workplaces. Here men, more than in other workplaces, find it difficult to be associated with competences, attitudes, or behaviours that have a female gender-code (Eveline, 2001, 1989; Gherardi \& Nicolini, 2000; Ely \& Meyerson, 2008; Somerville \& Abrahamsson, 2003) or have associations with unmanliness (Connell, 1995). As a result, we can see an interesting and seemingly paradoxical tendency that workplaces and work tasks introduced as a result of automation, computerisation, and robotisation can undergo a process of "feminisation" while the men hang on to the old technology (Olofsson, 2010). One example of this is when the mining workers underground, half-jokingly give the remotecontrol workers sitting above ground nicknames such as "the velour workers" (Abrahamsson \& Johansson, 2006; Andersson, 2012), meaning that they are of a soft unisex type of men, almost feminine, and not 'real' workers. On the one hand, this trend opens up new gender 
constructions in industry; on the other hand, this trend can be seen as a symptom of a conservative organization, i.e., barriers to implementing the new technology, and therefore important to study and understand.

At workplaces with a more gender-balance, male workers may attempt to restore the existing local gender order, by telling macho-masculine stories, refusing to do 'women's work' or 'womanish work', and openly resisting women at the workplace (Abrahamsson, 2014; Eveline \& Booth, 2002; Lahiri-Dutt, 2012). In these workplaces, ideas about gender: femininities and masculinities, often are so conservative they can create trouble during organisational changes and the implementation of new technology (Abrahamson, 2002; Hollway, 1996; Collinson \& Hearn, 1996).

Gender is something people do and construct in social interactions (Gherardi, 1994; West \& Zimmerman, 1987, 2009), embedded in work identities, work organisations, and technology (Acker, 1990), formed by complex societal processes and notions of masculinity and femininity. Many attitudes, norms, and cultural symbols at work that are learned through workplace socialisation are connected to gender and the (unequal) gender order (Hirdman, 1988, 2001). Tacit collective agreements and a continuous dramatization of gender both restore and change our ways of seeing masculinity and femininity. This play does not become really visible unless the existing masculinity and femininity are threatened (Butler, 1990, 1993), such as in the transformation towards a digital industrial context. Even if such processes often are connected to the restoration of the unequal gender order they are situated in, these processes are continuously changing, and there is a possibility to challenge and transform these processes (Abrahamsson, 2014).

\section{Shaping an A and B labour market}

In the optimistic visions smart systems, automation, and remote control will take over dangerous as well as routine work, so that production personnel can focus on learning, creating, and valuing work tasks in a safe environment (Gill, 2014). Even if the development will not be as the positive visions predict, depending on how the new technology is developed and interpreted, there will most likely be new types of industrial work, new types of work environments, and thus new work environmental problems. For example, digital technology and remote control, together with the emerging global and sometimes boundary-less work, not only results in increased freedom to decide how and where to work, but also results in higher demands of availability, perhaps 24 hours a day, seven days a week. This change may blur the boundaries between work and private life. Moreover, since the ability to control and monitor the individual increases, there will be a risk of new psychosocial stress. An increased information flow and accessibility could also lead to anxiety and job strain (Hoonakker \& Korunka, 2014).

Other examples come from enhanced possibilities of production distribution, decentralisation, and outsourcing, both locally/regionally and in the global context. This 
creates dynamic systems of contractors, agency staff, and other actors temporarily active in the same physical workplace or in the same virtual/digital workplace. As mentioned above, the employment form as we know today might dissolve and be replaced with crowdsourcing and what can be called liquidised employment (Holtgrewe, 2014), complicating the coordination of work environment interventions and responsibilities (Johansson et al., 2010).

We might also expect that old work environmental problems will appear in new contexts, and for other groups of workers. Some workers may participate in shaping the systems, while others will become machine assistants, or handle the repetitive and low qualified work tasks that could not be integrated into the automated and smart systems and the learning organisation. Maybe it is time to revive the old debate about the A and B labour market (Braverman, 1974; Kern \& Schumann, 1974)?

\section{Future work: pathways and implications}

For citizens in a democratic societal context, it is a civil right to be involved in shaping their own future. For many, however, in organisational work contexts characterised less by democracy and more by hierarchical power asymmetries and (increasingly precarious) wage labour contracts, the diffusion of new technology into their working life is sometimes perceived as a rather deterministic process, where their discretion is viewed as very limited. Our ambition is to create awareness of what the new technology can mean and for whom, and at the same time generate knowledge that development is possible to influence and control. There is always room to manoeuvre, for shaping how new technologies can be useful and relevant to people and society. The social dimension must have a prominent place in this process, both in designing the technology and in analysing it from several perspectives.

However, there is no lack of knowledge about the significance of the social dimension. Based on extensive and relatively coherent international research on work environment and work organisation, it is possible to formulate a summary list of requirements, almost a utopian vision, of what constitutes sustainable work (cf. Johansson \& Abrahamsson, 2009). Such a list could for example include demands that, not only are physical risks and problems eliminated, and equipment and work sites are adapted to suit people's different physical and psychological set-up, and designed to make work easier, but employees also enjoy autonomy and a sense of participation and influence in matters both large and small. These involve being able to influence the division of duties and the pace and method of working, in relation to both other people and to the technical system used. The list could also include that the work and workplace provide physical, intellectual and cultural stimulation, variety, opportunities for social interactions, context and opportunities for learning and for personal and professional development. Here, workloads, demands, and challenges (both physical and psychological) are balanced at a reasonable level. The list would also include gender equality, fairness, respect, trust, democratic leadership, and open communication and opportunities for enjoyment and social support for all employees. There should also be good opportunities 
for a fair, stable and predictable income and to combine work with a rich and sustainable life outside of work.

To conclude, the vision of sustainable work is known and accepted by most people. It is rather the road that is unknown and filled with some dangers and pitfalls. The design of new technology and new work organisation must be harmonised, with both good working conditions and efficient production that can compete in a global market, but the quite optimistic scenario described in the Industry 4.0 texts is not likely to become a reality by itself. New technology has not in itself a particular way to alter the effectiveness or working conditions, whether positive or negative. To enable a positive development, the technical and organisational development needs also to include knowledge of the human, the working environment and the organisation of work, both the formal and informal organising.

Industry 4.0, essentially a technology-driven vision, generally refers to a technological revolution with a strong focus on production rationalisation, but we can also see that the organisational recommendations set up for the implementation of Industry 4.0 (e.g., production flow, connected processes and systems, horizontal integrated and flexible organisation, learning and production standardisation, and diagnosis) (see Kagerman et al. 2013) have clear similarities with BPR, The Boundaryless Organisation, Learning Organisation, TBM, TQM, Six Sigma, and Lean. Therefore, there is a need for critical organisational analyses, discourse analyses, analyses of embedded conflicts in Industry 4.0, power shifts, and invisibility of power. In addition, there is a need for analyses related to other current organisational trends (e.g., centralisation, monitoring, requirements for voluntary, storytelling, and corporate branding) and wider social changes.

In general, the technical development is positive, but there are many questions that must be clarified, and we have discussed four of them. The development cannot and should not be stopped, but it requires reflections and considerations, so we do not create more problems than we solve. Research has an important role to play, when new technology should be valued and introduced, but that role is not pre-given to us; we have to mark our position by highlighting issues that are perceived as important and relevant. We cannot let the Industry 4.0's advocates set the discourse, alternative questions must be asked, other type of experts, such as academics, must be engaged, and alternative issues must be communicated and discussed by a wider audience. In the title of the article, we ask the question: The wolf is coming or God's gift to mankind? In order to experience sustainable work, we as researchers sometimes have to take on the role of the wolf, and ask uncomfortable questions.

\section{References}

Abrahamsson, L. (2002). Restoring the order: Gender segregation as an obstacle to organisational development, Applied Ergonomics, Volume 33, Issue 6, November 2002, pp. 549-557

Abrahamsson, L. (2006). Exploring construction of gendered identities at work, pp 105-121. In Billet, Stephan; Fenwick, Tara \& Somerville, Margaret (eds.). Work, Subjectivity and Learning. Understanding Learning through Working Life. Dordrecht: Springer. 
Abrahamsson, L. (2014). Gender and The Modern Organization, Ten Years After. Nordic journal of working life studies, 4(4), Dec 2014, 109-136.

Abrahamsson, L. \& Johansson, J. (2006). From Grounded Skills to Sky Qualifications, Journal of Industrial Relations Vol. 48(5)

Acker, J. (1990). Hierarchies, Jobs, Bodies, Gender and Society. 4:4, 139-158.

Andersson, E. (2012). Malmens manliga mysterium. Luleå tekniska universitet

Berner, B. (2003). Vem tillhör tekniken? (red.) Arkiv: Lund, 2003, 311s

Blauner, R. (1964). Alienation and Freedom. Chicago: UCP

Braverman, H. (1974). Labour and Monopoly Capital. New York: Monthly Review Press.

Bright, J. (1958). Automation and management. Harvard Business School, Boston

Butler, J.P. (1990). Gender Trouble: feminism and the subversion of identity. Routledge: New York.

Butler, J.P. (1993) Bodies that Matter: on the discursive limits of "sex". New York: Routledge.

Collinson, D. (1992) Managing the shop floor. Berlin: Walter de Gruyter

Collinson, D. \& Hearn, J. (eds.). (1996). Men as Managers, Managers as Men. London: Sage.

Conell, R.W. (1995). Masculinities. Los Angeles: University of California Press.

Ely, R.J. \& Meyerson, D. (2008). “Unmasking Manly Men”. Harvard Business Review, Jul 01, 2008.

Eveline, J. (1989). Patriarchy in the Diamond Mines. Murdoch University. Australia.

Eveline, J. (2001). "Keeping the Boys Happy": Managerialism and the Resistance of Women Miners in Australia. Unpublished paper, Gender, Work and Organization Conference, University of Keele, UK.

Eveline, J. \& Booth, M. (2002). Gender and Sexuality in Discourses of Managerial Control, Gender, Work and Organization. Vol. 9 No. 5 November 2002

Fältholm, Y. (1998). Work, Cooperation and Professionalization, Luleå University of Technology

Gherardi, S. (1994). The gender we think, the gender we do in our everyday organisational lives. Human Relations, $47,6,519-610$

Gherardi, S. \& Nicolini, D. (2000). The organizational learning of safety in communities of practice. Journal of Management Inquiry, 9(1), 7-18.

Gill, S. (2014). Industry prepares for the next industrial revolution. Control Engineering

Hirdman, Y. (1988). Genussystemet: Reflexioner över kvinnors sociala underordning. Kvinnovetenskaplig tidskrift KVT nr 31988.

Hirdman, Y. (2001). Genus - om det stabilas föränderliga former. Malmö: Liber

Hollway, W. (1996). Masters and Men in the Transition from Factory Hands to Sentimental Workers. I Collinson D and Hearn J, Men as Managers, Managers as Men. London: Sage

Holtgrewe, U. (2014), New new technologies: the future and the present of work in information and communication technology, New Technology, Work and Employment, 29(1), 9-24.

Hoonakker, P., \& Korunka, C. (2014). Introduction. In Korunka, C. \& Hoonakker, P. The impact of ICT on quality of working life (pp. 1-7). Dordrecht: Springer

Howe, J. (2008). Crowdsourcing, New York: Crown Publishing Group.

Johansson, B., Johansson, J. \& Abrahamsson, L. (2010). Attractive workplaces in the mine of the future: 26 statements. International Journal of Mining and Mineral Engineering. 2010; vol. 2, nr. 3, s. 239-252

Johansson, J \& Johansson, L. (2009). The good work. Applied Ergonomics, 40(4), July 2009, 775-780.

Johansson, J. (1986). Teknisk och organisatorisk gestaltning, Luleå tekniska universitet. 
Johansson, J., Abrahamsson, L. \& Johansson, S. (2013). If you can't beat them, join them? The Swedish trade union movement and lean production. Journal of Industrial Relations 55(3), 2013.

Kagerman, H., Wahlster, W. \& Helbig, J. (2013.) Recommendations for implementing the strategic initiative Industry 4.0. Acatech, München.

Kern, H. \& Schumann, M. (1974). Industriearbeit und Arbeiterbewusstsein, (EVA) Frankfurt am Main/Köln

Kern, H. \& Schumann, M. (1987). Limits of the Division of Labour, Economic and Industrial Democracy vol. 8, no. 2, $151-170$

Lahiri-Dutt, K. (2012). Digging women: towards a new agenda for feminist critiques of mining. Gender, Place and Culture, 2012, Vol. 19, No. 2, 193-212

Lahiri-Dutt, K. (2007). Roles and status of women in extractive industries in India: Making a place for a gendersensitive mining development. Social Change 2007 37: 37.

Lasi, H., Fettke, P. D. P., Kemper, H. G., Feld, D. I. T. \& Hoffmann, D. H. M. (2014). Industry 4.0. Business \& Information Systems Engineering, 6(4), 239-242

Lysgaard, S. (1961). Arbeiderkollektivet, Oslo: Universitetsforlaget

Mellström, U. (2004). Machines and masculine subjectivity, technology as an integral part of men's life experiences, in Men and Masculinities, (eds.) Faulkner, W \& Lohan M, Special Issue: Masculinities and Technology, volume 6, Number 4, April 2004, 368-383.

Olofsson, J. (2010). Taking place - augmenting space, Luleå University of Technology

Polanyi, M. (1967). The tacit dimension, Routledge, London

Regeringskansliet. (2016). Smart Industry - a strategy for new industrialisation for Sweden

Romero, D., Stahre, J., Wuest, T., Noran, O., Bernus, P., Faet-Berglund, A. \& GoreckyY, D. (2016). Towards an operator 4.0 typology: A human-centric perspective on the fourth industrial revolution technologies. International Conference on Computers \& Industrial Engineering CIE 29-31 Oct 2016.

Somerville, M. \& Abrahamsson, L. (2003). Trainers and Learners Constructing a Community of Practice, Studies in the Education of Adults, Volume 35, No 1, 2003, 19-34

Taylor, P. (2010). The Globalization of service work, in Thompson P and Smith C (eds.) Working Life, Palgrave MacMillan, London, 244-268.

Thompson, P. (2013). Financialization and the workplace, Work, Employment and Society, 27: 3, 472-488.

West, C. \& Zimmerman, D.H. (1987). Doing Gender, Gender and Society, Vol. 1, No. 2, 125-151

West, C. \& Zimmerman, D.H. (2009). Accounting for Doing Gender, Gender \& Society, 2009; 23: 112-122

Whitehead, S.M. (2002). Men and Masculinities. Cambridge: Polity Press

Willis, P. (1979). Shop flour culture, masculinity and the wage form. I Clark, J., Chricher, C. \& Jonson, R. (red) Working Class Culture, London: Hutchinson.

\section{About the Authors}

Jan Johansson is Professor in Industrial Work Environment since 1994. In 1999 Johansson was appointed as Honorary Visiting Professor at the School of Industrial Relations and Organisational Behaviour, University of New South Wales, Sydney, Australia. He has been a member of the Swedish Research Council (2001-2003) and the Swedish Research Councils 
Ethical Committee. Johansson has extensive experience of mining research, and has been WP leader in a number of EU mining projects.

Lena Abrahamsson is Chair Professor in Human Work Science since 2016 and before that Chair Professor in Gender \& Technology since 2013. Abrahamsson is currently Dean at Faculty of Technology. Abrahamsson has been Vice Chairman of the board of FORTE, member of the Swedish Work Environment Authority's advisory council, member of the Swedish government's commission for gender equality in working life. Abrahamsson's main research areas cover production and organisational changes, workplace learning and gender issues in industrial companies: with a strong focus on mining. 